\title{
Vindesine-Mitoxantrone (VM) Versus Vindesine-4'- Epidoxorubicin (VE) in Metastatic Breast Cancer: A Prospective Randomized Trial

\begin{tabular}{|l|l|l|}
\hline H. & Hausmaninger $^{\mathrm{a}}$ \\
\hline M. & Lehnert $^{\mathrm{b}}$ \\
\hline
\end{tabular}

for the Breast Cancer Cooperative Group ${ }^{1}$ ancology Unit, General Hospital, Salzburg, Austria ${ }^{b}$ 3rd Dept. of Internal Medicine, General Hospital, Graz, Austria

\section{Schlüsselwörter}

Mammakarzinom

Kombinationschemotherapie

Vindesin

Mito-xantron

4'-Epidoxorubicin

\section{Zusammenfassung}

182 Patientinnen mit metastasierendem Mammakarzinom erhielten innerhalb einer randomisierten Studie V $\left(3 \mathrm{mg} / \mathrm{m}^{2}\right.$ i.v.) und $\mathrm{M}\left(10 \mathrm{mg} / \mathrm{m}^{2}\right.$ i.v. $)$ oder $\mathrm{E}\left(40 \mathrm{mg} / \mathrm{m}^{2}\right.$ i.v. $)$ alle 3 Wochen $3 \mathrm{mal}$ und anschließend alle 4 Wochen. Die Patientinnen wurden nach dem dominanten Metastasierungstyp und in Abhängigkeit von einer zytostatischen Vorbehandlung stratifi-ziert. In einer präliminaren Analyse findet sich ein signifikanter Unterschied in der Alopezierate (WHO-Grad 3 oder 4) zugunsten der Kombination VM. Gastrointestinale, hämatologische und neurotoxische Nebenwirkungen waren relativ geringfügig und für beide Gruppen ähnlich. Von 114 auswertbaren Patientinnen erreichten in der Gruppe VM 26\% und in der Gruppe VE 34\% eine komplette oder partielle Remission (n.s.). Hinsichtlich progressionsfreiem Intervall und Überleben finden sich keine Unterschiede zwischen den beiden Gruppen. Beide Behandlungsregime erscheinen gut verträglich und ähnlich effizient. Wegen der noch kurzen Beobachtungszeit erscheinen jedoch Schlußfolgerungen verfrüht.

Requests for reprints to: Dr. med. H. Hausmaninger, Onkologische Ambulanz, Landeskrankenanstalten, A-5020 Salzburg (Austria)

Summary and Key Words

182 patients with metastatic breast cancer were randomized to $\mathrm{V}(\mathrm{mg} / \mathrm{m} 2$ i.v. $)$ and $\mathrm{M}(10 \mathrm{mg} / \mathrm{m} 2$ i.v.) or $E(40 \mathrm{mg} / \mathrm{m} 2$ i.v.) every 3 weeks $\times 3$ and then every 4 weeks; they were stratified by sites of disease (visceral, bone, or soft-tissue dominant) and by prior chemotherapy. In a preliminary analysis there is a significant difference regarding frequency of alopecia (WHO Grade 3 or 4) favoring regimen VM; gastrointestinal, hematologic and neurotoxic side effects were mild and similar for both groups. Of 114 evaluable women there is a response rate (CR + PR) of $26 \%$ and $34 \%$ for VM and VE respectively (n.s,), and there is no significant difference between the 2 groups in time to progression and survival. Both regimens are well tolerated and seem to be equally effective. The median follow-up time is too short to draw final conclusions.

Breast cancer - Combination chemotherapy trone - 4' -Epidoxorubicin

Vindesine - Mitoxan-

Conventional chemotherapy with CMF regimens (cyclophos-phamide, methotrexate, 5fluorouracil) or doxorubicin-contai-ning combinations induce objective tumor regression in 50 $70 \%$ of patients with metastatic breast cancer [3-7]. Newer strategies of effective treatment 
include the development of less toxic chemotherapeutic agents, such as vindesine, mitoxantrone and 4'-epidoxorubicin [1], In order to compare the efficacy and toxicity of mitoxantrone and 4'epidoxorubicin in combination with vindesine we initiated a randomized multicenter trial.

Patients and Methods

Patients with metastatic breast cancer, seen at the participating institutions, were entered into this randomized trial; they were stratified by sites of disease (visceral, bone or soft tissue dominant) and by prior chemotherapy. Eligibility criteria for entry included histologically confirmed breast cancer with evaluable or measurable disease, Kar-nofsky performance status greater than 40, and expected survival of at

1 Participating investigators:

M. Fridrik (Allg. Krankenhaus Linz), R. Haidinger (Landeskrankenhaus Steyr), H. Hausmaninger (Landeskrankenanstalten Salzburg),

W. Hehenwarter (KH d. Elisabethinen, Linz), B. Knittel (LKH

Feldkirch), M. Lehnert (LKH Graz), D. Manfreda (LKH Klagen-

furt), G. Michlmayr (KH d. Barmh. Schwestern, Linz), H. Samonigg

(Med. Univ. Klinik Graz), L. Schiller (LKH Vöcklabruck), P. Sevelda

(Univ.-Frauenklinik Wien), R. Spinka (Kaiser-Franz-Josef-Spital,

Wien), G. Steger (Chemother. Univ.-Klinik Wien), and

A. Neiss (Inst. f. Biostatistik u. Dokumentation, Univ. Innsbruck).

least 3 months, normal bone marrow function (leukocyte count of $\geq 4,000 / \mathrm{mm} 3$ and platelet count of $\geq 100,000 / \mathrm{mm} 3$ ), adequate liver and renal function. Patients must not have had prior history of congestive heart failure or myocardial infarction. Exclusion criteria also included patients with CNS metastases, osteoplastic lesions only, concurrent malignancies of other sites, prior treatment with anthracyclines, mito-

Table I. Characteristics of randomized patients

Characteristics

$\mathrm{VM}^{*}$

yjj**

Total patients entered (n)

92

90

Mean age (years)

60.0

58.0

Menopausal status (\%)

Premenopausal

23

17

Postmenopausal

77

83

Estrogen receptor status (\%) 
$\mathrm{ER}+$

55.8

58.7

ER-

44.2

41.3

Disease-free interval (months)

23

22

Mean performance status (K. I.)

80

90

Prior chemotherapy (\%)

28

35

Prior hormonal therapy (\%)

58

49

Prior radiotherapy (\%)

28

21

Dominant site of disease (\%)

Visceral

71

67

Osseous

23

26

Soft tissue

6

7

* Vindesine-mitoxantrone

** Vindesine -4 '-epidoxorubicin

60

Hausmaninger, Lehnert: Combination Chemotherapy in Breast Cancer

xantrone or vindesine and endocrine therapy, chemotherapy or radiotherapy within 4 weeks before entering the study. Pre treatment evaluation included physical examination, full blood counts, blood chemistry, ECG, chest X-rays, sonography and appropriate radiographs for 
measurement of disease. Radionuclide scans or echocardiograms were optional. Blood counts and ECG were repeated prior to each treatment course, the remaining after 3 cycles of therapy. Treatment consisted of either mitoxantrone $(10 \mathrm{mg} / \mathrm{m} 2$ i.v. $)$ or 4 '-epidoxorubicin $(40 \mathrm{mg} / \mathrm{m} 2$ i.v. $)$ in combination with vindesine $(3 \mathrm{mg} / \mathrm{m} 2$ i.v.) every 3 weeks $\times 3$ and every 4 weeks thereafter. Standard dose modifications for dose reduction or discontinuation of therapy were used. All patients continued on therapy until evidence of progressive disease or until a cumulative dose was reached $(160 \mathrm{mg} / \mathrm{m} 2$ for mitoxantrone and $1,000 \mathrm{mg} / \mathrm{m} 2$ for 4 '-epidoxorubicin). Toxicity was graded according to WHO criteria [9]. Assessment of response was performed after 3 cycles using standard UICC criteria [8]. Time to progression was measured from randomization to the occurrence of progression or death.

Results

Between December 1985 and August 1987182 patients were randomized, and data from a preliminary analysis are presented here. Patient characteristics and previous therapy are listed in table I. There are no statistically significant differences for the 2 groups of patients.

160 patients are now evaluable for toxicity. $22(27.8 \%)$ of VM treated patients and $20(24.7 \%)$ in the VE arm developed leukopenia (WBC $<4,000$, grade 1-2) at the time of the next cycle, but there was a higher frequency of WBC less than 2,000 cells $/ \mu 1$ in the VM group ( $40 \% \mathrm{vs} .14 \%)$. Thrombocytopenia was rare for either treatment group (platelet count $<1 \mathrm{OO}, \mathrm{OOO} / \mu \mathrm{l}, 1.3 \%$ for both groups). With respect to nonhematologic toxicity there was a statistically significant difference in the frequency of alopecia. Moderate or severe alopecia (grade 3-4) occurred in $16 \%$ of VM-treated patients as compared to $45 \%$ of patients treated with VE $(\mathrm{p}=0.003)$. For nausea (grade $3-4,17 \%$ ) or vomiting $(8 \%)$ and diarrhea (4\% vs. $0 \%$ ) there was no difference in the incidence and severity of adverse experiences. No patient got moderate to severe stomatitis. Neurotoxicity was observed in $24 \%$ of patients in the VM arm and $11 \%$ in the VE group. Of 114 patients evaluable for response, the objective remission rate (CR + PR) for VM was $25.9 \%$ and $33.9 \%$ for VE. This difference is not statistically significant. No change was recorded in $46.3 \%$ and $48.3 \%$ for VM and VE respectively. There were no significant differences between the 2 treatment groups regarding response and prior therapy or dominant site of disease.

The median follow-up period in this study is now 6 months. For both groups of patients the median time to progression is 6 months, and there is no difference in survival yet.

Discussion

After a plateau with regard to response rates, response duration and survival using standard chemotherapeutic agents in the treatment of advanced breast cancer had been reached, newer strategies include the development of less toxic drugs to improve the quality of life of patients. One of these drugs is vindesine. The activity of vindesine is similar to that of vinblastine and superior to vincristine [2]. The anthroquinone mitoxantrone has been compared in multiple randomized trials with doxorubicin either as single agent or in combination regimens $[10,11]$. Mitoxantrone is associated with less alopecia, gastrointestinal symptoms and less cardiotoxicity. The anthracycline 4'-epidoxorubicin also seems to be as active as doxorubicin but less toxic [12, 13]. The aim of our study was to compare mitoxantrone and 4'-epi-doxorubicin in combination chemotherapy with vindesine regarding efficacy and toxicity. The data presented demonstrate a slightly lower response rate of mitoxantrone-treated patients but this difference is not statistical significant. There is also no difference in time to progression between the 2 regimens. Mitoxantrone caused significantly less alopecia and equal nausea and vomiting than 4' epidoxorubicin combined with vindesine. Myelosuppression and neurotoxicity was mild and comparable for both groups. 
As these data were obained from a very preliminary analysis -the median follow-up time is only 6 months - final conclusions cannot be drawn. Until further, long-term follow-up can be obtained, the study is continuing.

References

Henderson, I. C. et al.: New agents and new medical treatments for advanced breast. Cancer. Sem. Oncol. 1: 34-64 (1987).

Yap, H. Y; Blumenschein, G. R.; Hortobagyi, G. N. et al.: A randomized comparative study of vinblastine (vlb), vindesine (vds) and vincristine (vcr) in patients (pts) with refractory metastatic breast cancer. Proc. ASCO 22: 441 (1981).

Cooper, R.: Combination chemotherapy in hormone resistant cancer (Abstract

). Proc. Am. Ass. Cancer Res. 10: 15 (1969).

Canellos, G. B. et al.: Combination chemotherapy for metastatic breast carcinoma. Prospective comparison of multiple drug therapy with 1-phenylalanine mustard. Cancer 38: 1882-1886 (1976).

Brambilla, C. et al.: Response and survival in advanced breast cancer after two non-crossresistant combinations. Br. med. J. 1: 801-804 (1976).

Tormey, D. C: Adriamycin in breast cancer: An overview of studies. Cancer Chemother. Rep. 6: 319-327 (1975).

Tranum, B. L. et al.: Adriamycin combinations in advanced breast cancer. A Southwest Oncology Group study. Cancer 49: 835-839 (1982).

Manual of cancer chemotherapy UICC. Techn. Rep., vol. 56: 17-26 (Geneva, 1981).

WHO Handbook for Reporting Results of Cancer Treatments, WHO Offset Publication 48 (Geneva, 1979).

Neidhart, J. A. et al.: A randomized study of mitoxantrone and adriamycin in breast cancer patients failing primary therapy. Proc. ASCO 1: 86 (1982).

Stewart, D. et al.: A randomized comparison of cyclophosphamide - mitoxantrone - 5-

fluorouracil versus cyclophosphamide - doxorubicin - 5-fluorouracü in advanced breast cancer:

Preliminary observations. Sem. Oncol. 11: suppl. 1, 23-27 (1984).

Ganzina, F.: 4'-Epidoxorubicin, a new analogue of doxorubicin: A preliminary overview of preclinical and clinical dates. Cancer Treat. Rev. 10: 1-22 (1983).

Bonfante

V. et al.: Toxic and therapeutic activity of 4'-Epidoxo-rubicin. Tumori 68: 105-Ill (1982). 